\title{
Escola, religião e intolerância: resultados de um trabalho de extensão na periferia de Campinas-SP
}

\section{School, Religion and Intolerance: results from an extension work in the outskirts of Campinas-SP}

\author{
1 Vitor Barletta Machado \\ 2 Aline de Cassia Cappelozzi \\ 3 Luis Gustavo da Silva Córdoba
}

\footnotetext{
Professor extensionista da Faculdade de Ciências Sociais da PUC-Campinas (vitor.machado@puc-campinas.edu.br)

Graduada em Ciências Sociais pela Pontifícia Universidade Católica de Campinas

3 Graduando do curso de Ciências Sociais da Pontifícia Universidade Católica de Campinas.
}

\section{RESUMO}

O presente artigo apresenta os resultados e reflexões obtidos pela realização do projeto de extensão "Intolerância e violência religiosa: construindo a alteridade no ambiente escolar", apoiado pela Pontifícia Universidade Católica de Campinas (PUC-Campinas). O projeto se desenvolve na E.E. Reverendo Eliseu Narciso, na periferia de Campinas, visando auxiliar no estabelecimento de um ambiente de respeito mútuo, pautado no conceito de alteridade e na valorização dos Direitos Humanos. 0 artigo descreve as oficinas realizadas e apresenta alguns resultados, em paralelo com a reflexão sobre o cenário religioso na região de Campinas, inserindo a temática em seu contexto mais amplo. Os resultados preliminares das oficinas na escola sugerem que a premissa inicial do projeto, de que é necessário o conhecimento sobre o outro para desenvolver a alteridade, está correta, diante do retorno de professores e alunos revelando algumas melhoras na convivência cotidiana.

\section{Palavras-chave:}

1. Escola. 2. Intolerância Religiosa. 3 Violência. 4 Extensão. 5 Alteridade.

\begin{abstract}
This article presents the results and reflections of the project of extension "Intolerance and Religious Violence: building otherness in the school environment", supported by the Pontifical Catholic University of Campinas (PUC-Campinas). The project is developed in E. E. Reverend Eliseu Narciso, in the outskirts of Campinas, aiming to help in the building of an environment of mutual respect, based on the concept of alterity and the valorization of Human Rights. The article describes the workshops and presents some results, in parallel with the reflection on the religious scene in the region of Campinas, inserting the theme in a broader context. The preliminary results of the workshops at the school suggest that the initial premise of the project, which states that it's require the knowledge about the other to develop otherness, is correct, given the return of teachers and students revealing some improvement in daily living.
\end{abstract}

\section{Keywords:}

1 School. 2 Religious intolerance. 3 Violence. 4 Extension. 5 Otherness.

\section{Como você deve citar?}

MACHADO, Vitor Barletta; CAPPELOZZI, Aline de Cassia; CÓRDOBA, Luis Gustavo da Silva. Escola, religião e intolerância: resultados de um trabalho de extensão na periferia de Campinas-SP. Cadernos UniFOA, Volta Redonda, $\mathrm{n}$. 35, p. 63-74, dez. 2017. 


\section{APRESENTAÇÃO}

Este artigo reúne algumas reflexões feitas pela equipe do projeto de extensão "Intolerância e violência religiosa: construindo a alteridade no ambiente escolar", parte do programa de extensão da PUC-Campinas. A premissa principal da atividade de extensão é de que a violência resulta frequentemente da intolerância e que esta se expande onde não há alteridade. Compreendemos o conceito de alteridade, partindo de Lévi-Strauss:

A atitude mais antiga e que repousa, sem dúvida, sobre fundamentos psicológicos sólidos, pois que tende a reaparecer em cada um de nós quando somos colocados numa situação inesperada, consiste em repudiar pura e simplesmente as formas culturais, morais, religiosas, sociais e estéticas mais afastadas daquelas com que nos identificamos. (LÉVI-STRAUSS, 2008, p. 17)

A alteridade começa com a percepção dessa distinção indicada por Lévi-Strauss, mas sem cair no repúdio, que é o caminho para a o etnocentrismo, o acreditar na superioridade da sua própria cultura, de seus próprios valores. 0 etnocentrismo é o avesso da alteridade. Não conhecemos o outro, não entendemos sua trajetória e por isso ele nos aparece como estranho, incômodo e até mesmo ameaçador. E a persistência da ocorrência de diversos conflitos estimulados pela intolerância de fundo religioso foi o estímulo do projeto. Contatos feitos com a escola parceira da atividade, o E.E. Reverendo Eliseu Narciso, revelaram a existência de conflitos envolvendo intolerância religiosa, sendo o mais grave um caso de agressão à aluna praticante de candomblé nas proximidades da escola, mas com diversos conflitos ocorrendo dentro da sala de aula, entre os alunos e também destes com alguns professores. Por isso, o objetivo principal do projeto de extensão é o de auxiliar na construção de um ambiente de maior tolerância e respeito dentro da escola, mas não restrito a ela, de modo que se expanda às relações sociais mais amplas de alunos e professores, em um efeito multiplicador ${ }^{4}$.

Para atingirmos o objetivo principal, traçamos outros complementares que contribuem para o andamento das diferentes oficinas realizadas. 0 primeiro era a pesquisa por informações sobre os princípios orientadores das diferentes religiões do cenário religioso campineiro, visando fornecer subsídios ao diálogo com os alunos em sala de aula. 0 segundo era o estudo da Declaração Universal dos Direitos Humanos em paralelo com os princípios do Plano Nacional de Educação, visando promover a compreensão mais adequada do seu significado, indispensável ao desenvolvimento da noção de alteridade. Tais documentos serviram de base para a reflexão sobre as crenças religiosas dos alunos, enfocando na percepção de valores universais, com o propósito de estimular o sentimento da importância do respeito às diferenças na construção de um mundo mais pacífico. 0 propósito não era o de apresentar a reflexão sobre os Direitos Humanos de maneira sistemática, mas de estimular os alunos a entenderem que esses são seus próprios direitos, refletindo sobre se eles estão sendo respeitados em nossa sociedade.

Todas as informações obtidas foram sistematizadas para utilização nas diferentes oficinas realizadas com os alunos, o que será objeto de apresentação da próxima parte.

4 Importante ressaltar que a escola emite carta de aceite, assinada pela direção, para iniciarmos os trabalhos com os alunos. Todos os nomes de participantes foram suprimidos. Este artigo não parte, portanto, de atividade de pesquisa, mas de observações feitas partindo do material coletado em projeto de extensão autorizado pela escola. Configura-se metodologicamente como observação participante, reflexões sistemáticas feitas pela vivência de situações cotidianas, não incorrendo nos casos de submissão necessária ao sistema CEP/CONEP, conforme os itens VII e VIII do parágrafo único do artigo $1^{\circ}$ da resolução 510, de 07 de abril de 2016 


\section{METODOLOGIA - APLICAÇÃO DAS OFICINAS E OBSERVAÇÃO PARTICIPANTE}

O projeto propõe a realização de quatro oficinas, divididas em dois blocos. Para facilitar a execução e ao mesmo tempo ampliar os seus efeitos, o trabalho é realizado com uma sala de cada vez, em dois encontros com intervalo de duas semanas, durante o horário de aulas. Aqui se revela a importância da parceria com a escola desde o início das atividades, nos concedendo acesso aos alunos, aos professores, mas também aos seus espaços e equipamentos. $O$ fato de trabalharmos com as turmas em horário de aula nos forneceu sempre um número bastante razoável de participantes, oscilando entre 20 e 30, reproduzindo parte da dinâmica cotidiana enfrentada pelos professores. 0 número de encontros e o intervalo entre eles foram estabelecidos, justamente para não prejudicar o conteúdo das aulas dos professores que nos cederam gentilmente o tempo.

As oficinas são as seguintes:

\section{Bloco I (primeiro encontro)}

- "Eu não conheço você" - Muitas vezes, os professores partem do pressuposto de que os alunos, por conviverem diariamente, conhecem os vários aspectos da personalidade e da vida dos colegas. Uma das premissas do projeto é acreditar que a violência é resultado da desinformação e da falta de conhecimento sobre o próximo. Por isso, buscamos verificar se alunos realmente conheciam as expectativas e dificuldades uns dos outros, suas histórias familiares. Solicitamos que contassem suas histórias, dizendo de onde vieram e onde querem chegar, através de um texto, uma história em quadrinhos, uma ilustração, sem qualquer restrição. A equipe de extensão, então, faz a seleção de alguma informação dentro dos trabalhos produzidos, solicitando que a turma tente identificar o autor. Tomamos sempre o cuidado de selecionar apenas informações menos sensíveis, como a cidade de origem e os planos para o futuro (como o curso superior que desejam cursar).

- "Humanos" - A segunda oficina do primeiro encontro tem o propósito de lidar especificamente com a questão dos Direitos Humanos, mas evitando o processo rotineiro de uma apresentação sistemática deles, fugindo do modelo cotidiano da sala de aula. Começamos pedindo aos alunos que digam o que sabem sobre os direitos humanos e para cada informação fornecida, variando muito de uma turma para outra, alguma reflexão é proposta, sempre no sentido de aproximar a discussão ao cotidiano dos alunos. 0 próximo passo é pedir que se reúnam em pequenos grupos para pensar sobre quais são as condições que consideram necessárias existirem para que todos as pessoas tenham uma vida digna e vivam em paz. No final, há a reflexão geral sobre as condições por eles escritas. Na condução dessa oficina, utilizamos notícias diversas de desrespeito aos Direitos Humanos, como elemento motivador.

\section{Bloco II (segundo encontro)}

- "Em que você acredita?" - A oficina de abertura do segundo encontro tem por objetivo refletir sobre a bagagem espiritual dos participantes. Incialmente sondamos a turma para entender como a questão do pertencimento está nela configurado, para, em seguida, pedir que escrevam, em duplas ou pequenos grupos por afınidade religiosa, quais são os principais elementos de sua fé, suas regras e preceitos. A proposta inicial era identificarmos fatores comuns entre as diferentes religiões, preparando o caminho da última oficina, mas como a maioria dos alunos não sabia responder adequadamente tais questões, alguns nem mesmo sendo capazes de nomear a religião que dizem seguir, conduzimos a discussão apresentando certos pressupostos gerais de diferentes religiões, traçando os paralelos entre elas. 
- "Fazer aos outros..." - Na última oficina, buscamos articular todas as discussões anteriores, destacando os pontos principais que foram debatidos nas outras oficinas. Instigamos que os alunos reflitam sobre o significado da frase "faça aos outros o que gostaria que fizessem com você", presente no discurso de diversas religiões e que nos conduz à construção do conceito de alteridade. Solicitamos aos alunos que reflitam sobre quais são, então, as condições que devemos construir, para que possamos viver todo o potencial dessa frase. Como última atividade, pedimos que deixem uma mensagem sobre todas as discussões que realizamos nos dois encontros, no formato livre (texto, desenho). Ao final do primeiro biênio desse projeto de extensão, as diversas atividades realizadas, bem como materiais distribuídos aos alunos, serão selecionadas e organizadas em um blog, para que todos possam acessar livremente e reproduzir os efeitos das oficinas.

$\mathrm{Na}$ condução das oficinas, a equipe sempre respeitou as particularidades de cada turma, de modo que algumas atividades sofreram pequenas adaptações de contexto, em função dos temas que tivessem despertado a maior participação dos alunos. Durante todas as atividades de extensão, adotamos a perspectiva da observação participante, inevitável diante do dinamismo das atividades. A observação participante é parte dos métodos de investigação da Antropologia, no campo da etnografia. Parte do pressuposto de que a presença do, nesse caso, extensionista/pesquisador em campo já é um elemento de quebra das situações cotidianas, de modo que se busca a posição de uma vivência com a comunidade. É muito diferente da noção de uma observação distanciada, sem interação. A metodologia participante é condição indispensável na situação de atividades de extensão, do mesmo modo que a condição de observador é inevitável para toda equipe, composta por profissional e graduandos em Ciências Sociais. Após os encontros, as impressões são registradas por escrito, com a maior quantidade de detalhes possível, seguindo também o pressuposto antropológico da manutenção de um "caderno de campo". Segue-se, então, que as observações são decorrentes da atividade de extensão e não o objetivo inicial da própria atividade, mas são inevitáveis e certamente instigadoras de diversas questões que auxiliam no aprimoramento do projeto e também na construção do conhecimento sobre suas temáticas.

\section{A ESCOLA E A RELIGIÃO: BREVE RETRATO DA REGIÃO DE CAMPINAS}

Campinas possui cerca de 1.164.098 habitantes, dos quais 636.703 se apresentam como católicos; 273.812, como evangélicos; e 35.625, como espíritas ${ }^{5}$. Mas a superioridade numérica dos católicos não significa uma adesão efetiva às celebrações religiosas, sendo comuns os casos de "católicos não praticantes", aqueles que não participam da vida de sua Igreja, apesar de continuarem se declarando dessa maneira. Já o grupo dos evangélicos é normalmente apresentado como mais ativo em suas atividades religiosas, reunindo uma grande quantidade de diferentes denominações, sem que exista algum tipo de unidade direta entre elas. Em Campinas, temos vários credos protestantes ou reformados, tais como: Igreja Luterana, Presbiteriana, Metodista, Episcopal Anglicana e Batistas. Existem também diversos igrejas evangélicas: Comunidade Evangélica Sara Nossa Terra, Igreja Cristã Maranata, Assembleia de Deus, Adventista do Sétimo Dia, Igreja Mundial do Poder de Deus, Igreja Universal do Reino de Deus, Congregação Cristã no Brasil, entre muitas outras. Para termos uma dimensão do total dos que se declararam evangélicos, $12,7 \%$ eram de origem pentecostal; $3,65 \%$, das igrejas evangélicas de missão; $1,25 \%$ não apresentavam sequer vínculo institucional e 0,65\% eram de várias outras denominações. Os dados nos revelam um contexto de vivência religiosa na cidade de Campinas majoritariamente cristão, mas os sem religião somavam 86.403 e o restante da população se divide em uma variedade de outras religiões: testemunhas de Jeová, candomblé e umbanda, islamismo, judaísmo, hinduísmo e outras. Temos ainda as religiões cristãs de outras denominações, como as Testemunhas de Jeová $(0,86 \%$ dos

5 Todos os dados foram retirados do IBGE. 
habitantes) e a Igreja de Jesus Cristo dos Santos dos Últimos Dias (0,2\%), sendo que esta, conhecida também como Igreja Mórmon, possui um dos seus principais templos em Campinas, inaugurado em maio de 1998, recebendo mais de 117 mil visitantes por ano. No Colégio Eliseu, até o momento, tivemos contato apenas com alunos que se declararam como católicos ou evangélicos, sem que tivessem sido capazes de nos apresentar qual denominação específica. Tal informação revela-se coerente com o perfil socioeconômico das praticantes das diferentes religiões no Brasil:

Há sete categorias de renda, desde no máximo um salário mínimo até mais de dez salários mínimos. De fato, como assinala a literatura, a maior parte dos membros das igrejas evangélicas advém de estratos sociais de baixa renda. Cerca de $67.7 \%$ dos evangélicos recebem mensalmente, no máximo, dois salários mínimos. Entre os dois segmentos sociais de maior renda (mais de seis salários mínimos), somente $8.9 \%$ optaram por se filiar ao credo evangélico. (BOHN, 2004, p. 297)

A Escola Estadual Reverendo Eliseu Narciso, conhecida somente como Eliseu, localiza-se no Distrito Industrial de Campinas (DIC), bairro que surgiu a partir do estímulo à transferência das indústrias do centro da cidade para bairros mais afastados, processo que promoveu a ocupação dessas áreas pela população, que tentava morar mais perto do trabalho. É uma região periférica, com muitos operários e muitos migrantes, que vieram para a cidade em busca de emprego. As médias salariais são baixas, $41,8 \%$ dos moradores da região ganhando até dois salários mínimos por mês e $37 \%$ não possuem renda alguma, conforme o último censo demográfico. 0 Eliseu ${ }^{6}$ tem aulas nos três turnos, ocupando suas 22 salas, com atuação de 63 professores e 18 funcionários. A escola tem sala de vídeo, sala de estudos, contando com equipamentos como computador e projetor. 0 ensino vai, atualmente, do sexto ano do fundamental até o último ano do médio, com cerca e 1400 alunos, entre 10 e 23 anos de idade. A história familiar dos alunos reflete as características gerais do bairro, com a forte presença de migrantes recentes de outras regiões do país, sempre em busca de trabalho. A estrutura familiar é diversificada, havendo os que vivem com ambos os pais, apenas com mãe, avós e tios. A maioria mora próximo à escola, algumas vezes em ocupações ilegais, tendo que recorrer a ligações clandestinas de água e energia, dependendo totalmente do transporte público ou tendo que ir a pé às aulas. A maioria dos alunos com que trabalhamos relatou que não contam com acompanhamento para os estudos em casa, pois seus responsáveis estão sempre trabalhando. Várias alunas apontam que são as responsáveis pelas tarefas do cotidiano de suas casas, em um cenário de repetição de papéis tradicionais de gênero. São diversas as carências vividas por esses jovens, desde as materiais, como a ausência de itens escolares (como régua, canetas hidrocor, lápis de colorir), mas, principalmente, as emocionais e afetivas, tendo sido comuns os depoimentos de ausência total de diálogo nas suas vidas.

\section{DISCUSSÃO SOBRE OS RESULTADOS}

Passamos a apresentar alguns dos resultados obtidos com as oficinas, bem como as diversas reflexões que suscitaram. Nos diversos relatos já colhidos para a realização da primeira oficina, apareceram informações que revelaram uma realidade muito mais variada e complexa do que um olhar superficial poderia supor. Vejamos o seguinte:

6 Todas as informações sobre o Eliseu e seu público foram obtidas em conversa com a equipe da escola. 
Figura 01

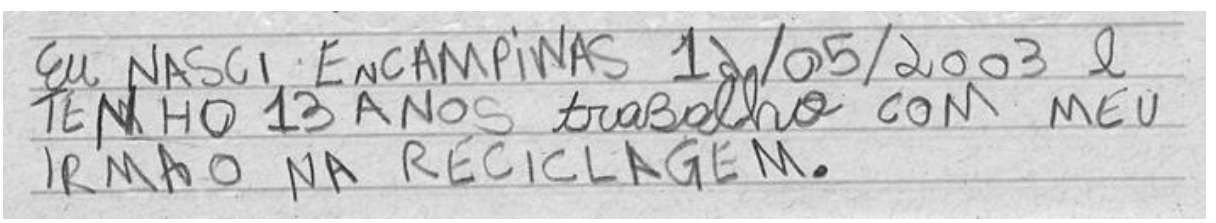

Fonte: próprio autor.

0 aluno teve grande dificuldade para escrever esse texto, mas não quis entregar a folha em branco, de modo que solicitou ajuda da equipe de extensão. Revelou-nos os desafios da realidade daquela comunidade, na figura de um jovem que estuda no período vespertino justamente por precisar trabalhar no período da manhã, ajudando o irmão. Frequentemente, o aluno nem mesmo vai às aulas, devido ao cansaço. 0 primeiro questionamento despertado foi sobre como podemos imaginar que ele pode conseguir aprender algo, como pode imaginar um futuro se o seu presente é tão massacrante? Fica evidente quando se constata que ele não chegou a escrever nada, nem mesmo a falar, sobre seus sonhos de futuro. Destacamos um segundo caso revelador:

Figura 02

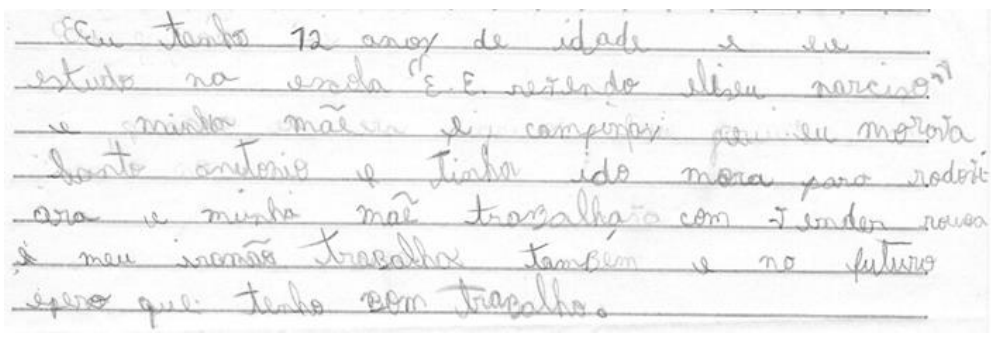

Fonte: próprio autor.

Com muita dificuldade, o aluno nos relatou a trajetória da família, destacando o empenho da mãe e do irmão trabalhando, enquanto que, para o futuro, só deseja um «bom trabalho», sem conseguir definir o que seria isso. Em tal contexto, a realização da extensão no colégio acabou atingindo um propósito inesperado: revelar aos alunos a existência da universidade, da possibilidade de outro tipo de trabalho através da continuidade do estudo. Tal possibilidade foi reforçada por uma feliz coincidência: uma das bolsistas da equipe havia sido aluna no Eliseu. Seu depoimento durante as discussões ajudou a indicar a possibilidade de se conseguir prosseguir nos estudos, ainda que precisando de muita ajuda e empenho pessoal. Também foi importante descobrirmos entre os alunos relatos de esperança, de conseguir seguir uma carreira de nível universitário: 
Figura 03

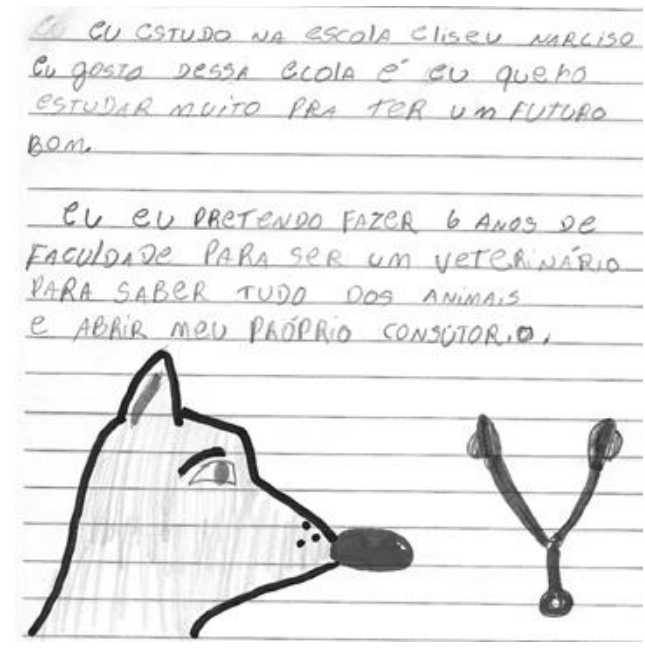

Fonte: próprio autor.

É o sonho de ser veterinário no futuro, expresso com clareza e simplicidade, por um jovem filho de uma mãe que se esforça trabalhando como diarista enquanto o pai trabalha em uma cozinha. A descoberta dessa vontade, da possibilidade de sonhar com o futuro mesmo diante de dificuldades, em turmas de alunos considerados sem interesse e indisciplinados, não foi um caso isolado.

Figura 04

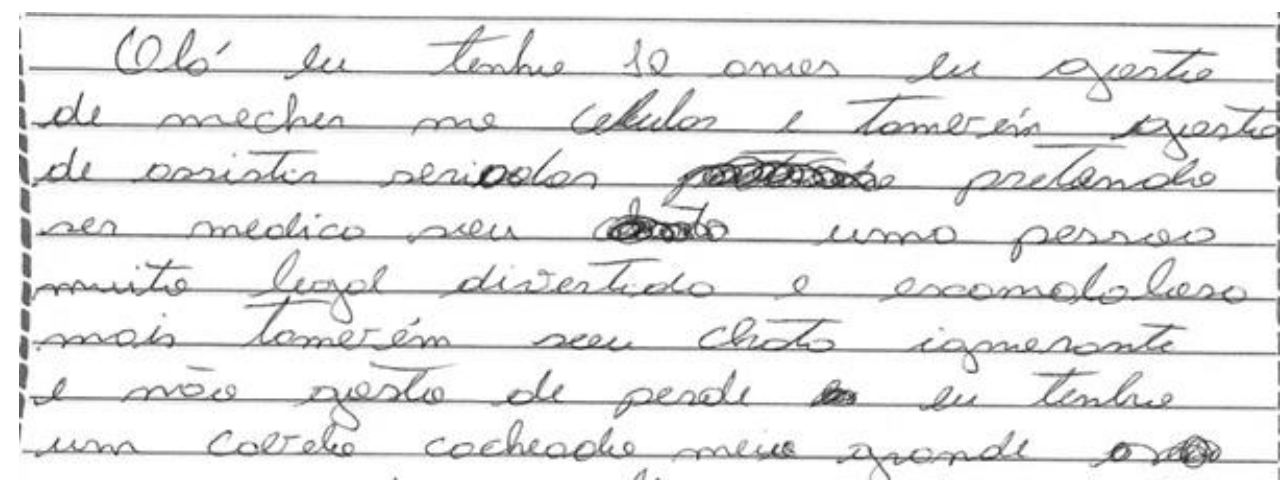

Fonte: próprio autor.

Ser médico, advogado, engenheiro, viajar para fora do Brasil. Praticamente todos os alunos com os quais trabalhamos revelaram o sonho de continuar estudando e ter uma profissão, uma vida melhor. Essa informação apareceu como surpreendente para os profissionais da escola, acostumados com os problemas cotidianos, com situações de indisciplina, de pouco interesse nas aulas. Revela uma dimensão assustadora da realidade escolar, na qual conteúdos são despejados sem que alunos e professores consigam se entender. A equipe de extensão descobriu nessas histórias um caminho novo de diálogo com os alunos, através dos seus sonhos, mostrando como a escola e a vida comunitária são extremamente importantes para a tentativa de realização de alguns deles. Alertamos que a concretização da vontade de se formar em um curso superior depende do aprendizado de vários conteúdos, o que passa necessariamente pela convivência na sala de aula, entre eles mesmos e também com os professores. Principalmente, ao se considerar o contexto periférico em que vivem, é a escola que deveria lhes mostrar o caminho da busca desses sonhos futuros, mas nem sempre ela é capaz de 
cumprir tal função, massacrada pela rotina de burocracias que visam tão somente o preenchimento de fichas e não o desenvolvimento do potencial dos alunos. Ocorre que serão justamente as mensagens religiosas que cumprem o papel de estimular o sonho, mas o qual se estabelece através da intervenção da fé e não do estudo em si mesmo, ou seja, se trata da busca de uma graça, de um pequeno milagre. E a quantidade de obstáculos a serem superados é tão grande que, de fato, sugere a intervenção de forças superiores. Vejamos mais um exemplo:

Figura 05

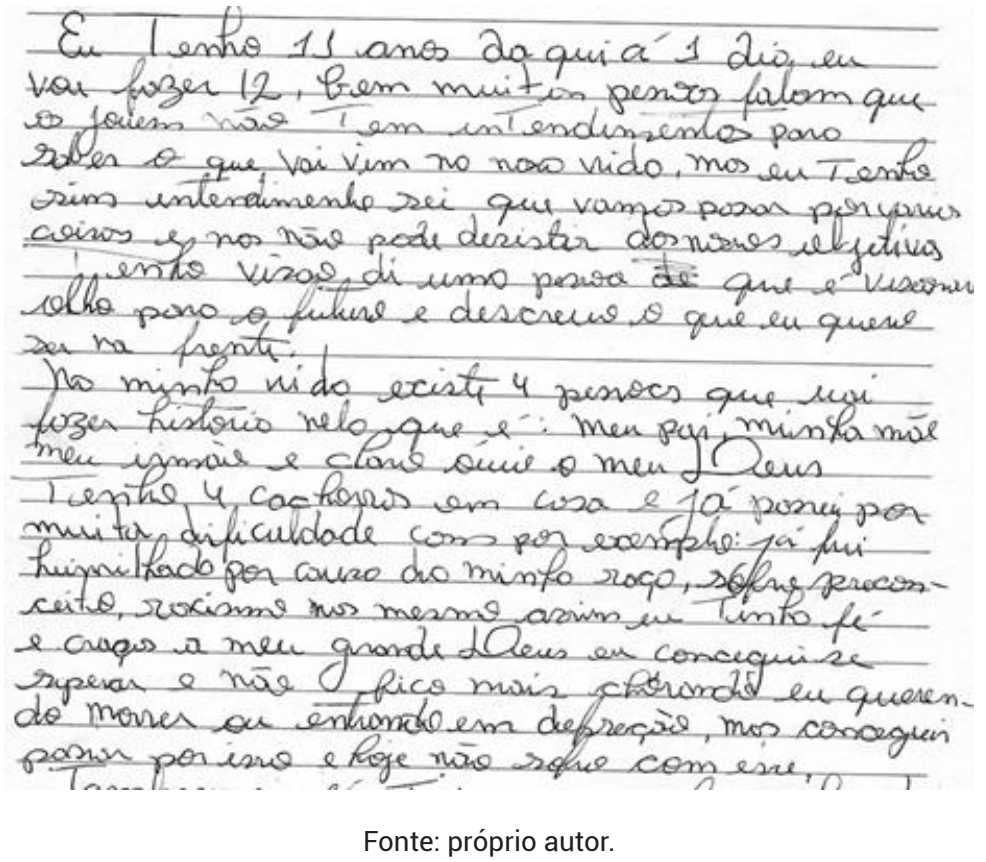

A fé surge como elemento que permite a esses alunos continuar a vida com esperança, manter a convicção na superação das dificuldades. 0 relato da figura 5 descreve humilhações sofridas por conta do racismo, que foram superadas através da fé: "já fui humilhada por causa da minha raça, sofro preconceito, racismo mas mesmo assim eu tenho fé e craças (sic, "graças") a meu Deus eu conceguise (sic, "consegui") superar e não fico mais chorando eu (sic) querendo morrer ou entrando em depreção (sic, "depressão")". A religião age como instrumento pelo qual violências e intolerâncias podem ser superadas, mas não no sentido da promoção de mudanças na realidade social, mas de uma solução individual, pela qual a pessoa consegue forças para continuar lutando por seus sonhos, uma solução de cunho privado. Para os alunos participantes das atividades, os momentos de discussão nas oficinas foram os primeiros em que eles puderam pensar sobre tais questões em coletividade, buscando soluções coletivas, capazes de promover mudanças mais abrangentes e duradouras. Ressaltamos, contudo, que tais transformações precisam ser debatidas na esfera pública, pois o desafio das condições sociais em que tais alunos vivem permanece uma realidade que só pode ser superada com um movimento mais amplo. Voltando ao trabalho de Bohn, vemos que "conforme aponta a literatura, os fiéis evangélicos - sobretudo os membros das denominações pentecostais - provêm de setores socioeconômicos significativamente desprivilegiados, tanto no que se refere à renda quanto ao nível de escolaridade." (BOHN, Ibid., p. 335). Uma realidade confirmada nas diferentes turmas que participaram das atividades de extensão que descrevemos, nas quais a presença de religiões do espectro evangélico era sempre majoritária. 0 mesmo vale para a renda das suas famílias, moradoras de uma das regiões mais pobres de Campinas, conforme o gráfico de Marchesini (2016, p. 124): 


\section{Gráfico 01}

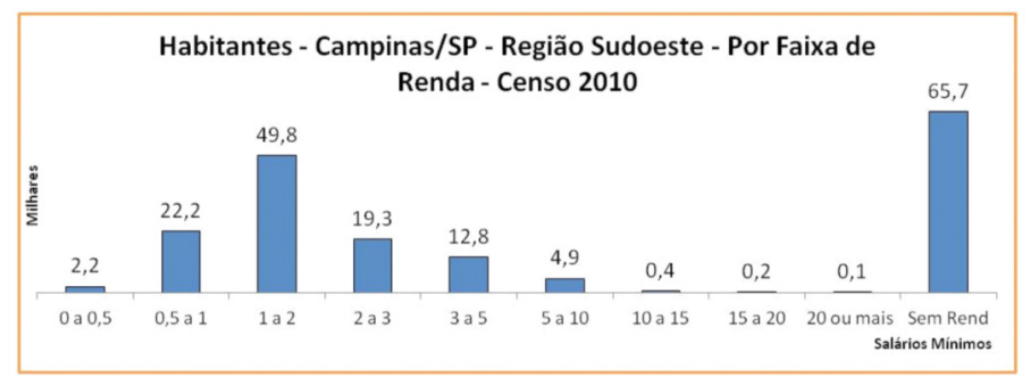

Fonte: Censo IBGE, 2010.

Os dados nos oferecem um retrato da realidade da região na qual a escola se localiza que também confirma as afirmações sobre o nível mais baixo de renda dos evangélicos, com cerca de $41,8 \%$ dos moradores recebendo até dois salários mínimos por mês e $37 \%$ que não possuem qualquer rendimento. O cenário reforça o papel central que a escola possui para as populações nas periferias das cidades, quer seja como a garantia de uma refeição no dia ou mesmo como um espaço para se sonhar em segredo o futuro, mais provavelmente ambos ao mesmo tempo. 0 desafio do trabalho em tais situações é grande, pois é necessário atender o aluno que está ali em situação de total carência, mas também aquele que ainda consegue sonhar com um futuro através do estudo. $E$ as religiões estão presentes na região, oferecendo conforto, possibilidades de sonho, orientações, que nem sempre se pautam pelo discurso da tolerância. Vejamos um relato:

Figura 06

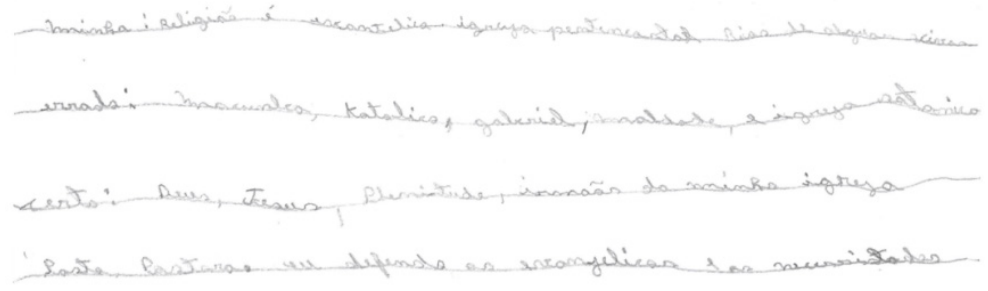

Fonte: próprio autor.

O discurso não é violento em si mesmo, mas revela que outras religiões foram apresentadas ao jovem como sendo erradas, como a "macumba" e a católica ${ }^{7}$. 0 problema de tal visão dualista com outras religiões é que várias das características indicadas positivamente para a sua própria religião, como acreditar em Deus, em Jesus e ajudar os necessitados, estão presentes naquelas também. Outro problema, já destacado neste trabalho, é que os alunos de todas as turmas demonstraram não conhecer nada sobre as doutrinas religiosas que afirmam seguir, limitando-se à apresentação de poucas normas de comportamento, como no exemplo seguinte:

7 Como lemos na imagem: "macunba, katolica" (sic) 


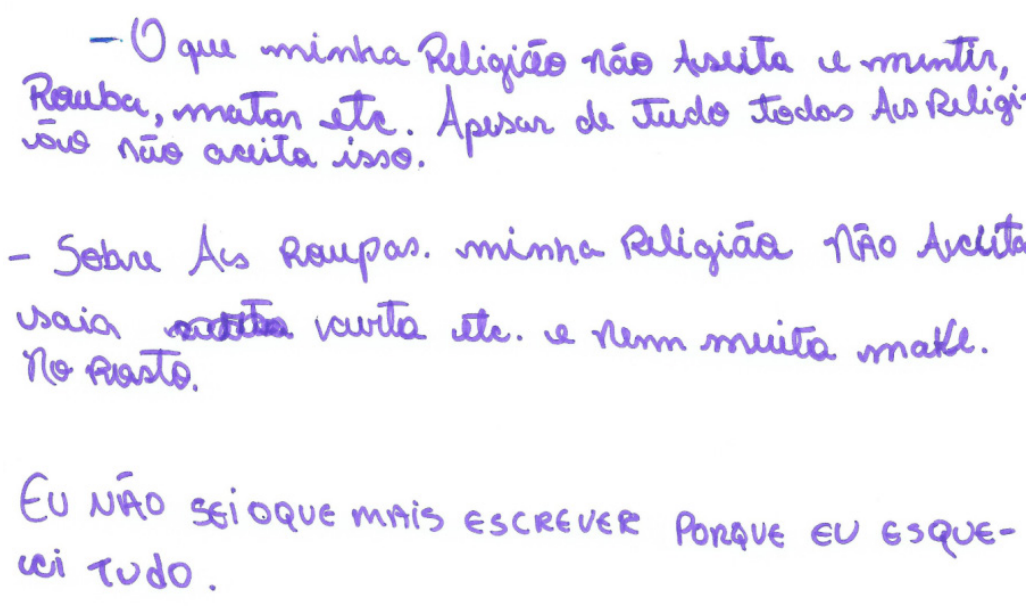

Fonte: próprio autor.

Várias coisas se destacam no texto anterior, começando pela percepção do seu autor de que não roubar e não matar são preceitos comuns de todas as religiões, Depois temos a proibição de utilização de saias curtas e maquiagem no rosto. E finalizando temos o reconhecimento de que ele não se lembra de mais nada, que esqueceu tudo. Não foi o único relato com essas características, na verdade, esse modelo foi a regra geral, indicando que os jovens estão memorizando apenas mensagens genéricas, comuns para diversas religiões, mas também presentes em discursos não religiosos, além daquelas restrições de comportamento que mais os afetam no dia a dia, como as de vestuário. A equipe de extensão constatou que, no que se refere à religião, os jovens não somente desconhecem aquelas que não praticam como também desconhecem as que dizem frequentar. 0 cenário de desconhecimento do outro pode ampliar as possibilidades de surgimento da violência, conforme já afırmado.

Após a apresentação do conceito de alteridade aos alunos nas oficinas, os resultados se revelaram promissores. A compreensão dos benefícios de uma realidade de respeito mútuo é imediata pelos alunos. Foi quando nos foi revelada outra dimensão daquela realidade, nos momentos em que os alunos se aproximavam com certa admiração, querendo entender como era possível para toda equipe de extensão se manter calma e sorridente, mesmo quando a sala fazia alguma bagunça. Em uma das abordagens, a aluna queria saber qual era o segredo para conseguir ficar calma da maneira como toda a equipe de extensão era, de não levantar a voz, pois ali na escola todos gritavam com todos. Tal é o motivo das discussões realizadas com os alunos durante as oficinas terem também abordado questões aparentemente distantes do tema intolerância e violência religiosa. Estávamos buscando identificar as diversas origens da intolerância, de modo que outras características, além da opção religiosa, eram parte necessária dos debates, como a discussão sobre a desigualdade de renda no Brasil ou sobre a situação da educação pública, as condições de moradia, as mudanças no mercado de trabalho, entre outros. Todos foram temas que surgiram, em um momento ou outro, nas diferentes salas, sempre refletindo o cenário socioeconômico daquela região da cidade.

\section{CONSIDERAÇÕES FINAIS}

A centralidade da religião como elemento de estímulo à luta pela superação das dificuldades na vida desses alunos deixa o baixo conhecimento de suas doutrinas como fator extra de preocupação. A lembrança presente eram somente as regras e normas de comportamento, principalmente associadas ao vestuário feminino, mas nem sempre apareciam os valores da paz, amor, respeito e solidariedade. 
Temos, então, uma religião como norma proibitiva, não como valor. A maioria das religiões presentes na cidade lida com o mesmo referencial teológico, o que poderia produzir uma sensação geral de unidade, que Negrão denominou de "mínimo denominador religioso comum", conceito que indica "a existência de uma cultura religiosa brasileira popular, que inclui um 'mínimo denominador comum' capaz de ser identificado pelo homem religioso nos diferentes cultos integrantes do campo." (NEGRÃO, 1997, p. 70). Entretanto, tais preceitos comuns escondem a variedade da vivência religiosa, ajudando a desenvolver um ambiente no qual a prática da alteridade é necessária, mas nem sempre realizada. 0 enfoque das oficinas era, justamente, apresentar as religiões como elemento construtivo na vida social e não como fator motivador da violência e intolerância, demonstrando que a maioria das religiões defendem valores que vão ao sentido contrário de tais práticas. Um dado animador nas oficinas foi que poucos alunos demonstraram posicionamentos intolerantes explícitos. Um caso exemplar foi de um aluno que manteve um discurso de intolerância religiosa, mesmo quando a turma já estava preparando suas mensagens finais do bloco II. 0 grupo o repreendeu, perguntando se ele não tinha entendido ou ouvido as reflexões. A resposta surpreendeu e entristeceu toda equipe de extensão: o aluno afirmou que, se chegasse em casa reproduzindo as nossas conversas sobre respeito e alteridade, contra a intolerância religiosa, apanharia do pai. Para esse aluno, pensar sobre Direitos Humanos era algo completamente fora da realidade cotidiana. Ele tinha nos ouvido, compreendeu que as religiões não deveriam ser geradoras de intolerância e violência, concordando com todos na turma com os valores religiosos de paz, amor ao próximo, fraternidade e solidariedade. Entretanto ele mesmo não vive uma realidade que the permita adotar uma postura tolerante em sala de aula e, provavelmente, fora dela. Isso sugere o papel que a religião pode exercer na formação da personalidade de cada um, mesmo que não seja através da real compreensão de seus valores, em um processo nem sempre percebido, principalmente por surgir associado a diversos outros elementos da realidade social circundante.

Além dos efeitos e resultados aqui apresentados, tivemos o retorno de alguns professores sobre os impactos da atividade de extensão nos alunos. O principal, que vale um destaque, veio do professor de história, pois foi justamente durante suas aulas que alguns conflitos e brigas haviam surgido envolvendo a temática religiosa. Relatou-nos que particularmente na turma onde a discussão com os alunos havia acontecido, por conta do estudo sobre o período da Reforma Protestante, a postura havia mudado. Antes os alunos já partiam para discussão e começavam a brigar à menor divergência, mas, após as oficinas, percebeu que eles param primeiro para ouvir e que, sempre que uma agitação começa, algum colega pergunta se eles já se esqueceram do que foi aprendido na oficina. Evidente que os resultados variam em cada turma. Foge às possibilidades deste projeto de extensão promover mudanças profundas e imediatas de comportamento, já que envolvem o histórico familiar de cada aluno, bem como a configuração das turmas na própria escola. Temos, contudo, que os professores que participaram da atividade e a própria coordenação da escola puderam descobrir outro aspectos da personalidade dos seus alunos, já que várias das histórias e sonhos que coletamos não eram conhecidas por eles. Pudemos reforçar a possibilidade de utilizar o ambiente escolar, espaço para ampliação dos saberes, em uma perspectiva mais crítica e menos tecnicista, visando à construção de uma sociedade melhor ou, pelo menos, de uma realidade melhor no bairro e nas famílias.

Finalizando essa reflexão, podemos afırmar que o projeto foi capaz de inserir a discussão pretendida, gerando impactos no cotidiano escolar, principalmente aos alunos participantes, pois foram tratados assuntos que não são abordados sistematicamente nas aulas das diferentes disciplinas. Além disso, serviu para revelar que o processo de ensino pode possuir um caráter menos opressor, menos preso ao formalismo dos conteúdos. Esperamos que a escola possa ampliar e reproduzir alguns dos elementos introduzidos pelas atividades de extensão em seu espaço. Pode ser um dos caminhos no combate não somente à intolerância religiosa no Brasil, mas a outras formas de violência. 


\section{REFERÊNCIAS}

BOHN, Simone R.. Evangélicos no Brasil: perfil socioeconômico, afinidades ideológicas e determinantes do comportamento eleitoral.Opinião Pública, [s.I.], v. 10, n. 2, p.288-338, out. 2004. FapUNIFESP (SciELO). http://dx.doi.org/10.1590/s0104-62762004000200006.

IBGE cidades. Disponível em: <http://cod.ibge.gov.br/A1G>. Acesso em: 22 out. 2016.

LÉVI-STRAUSS, Claude. Raça e história. 9. ed. Lisboa: Presença, 2008.

MARCHESINI, Isadora G. Relatório de Informações Sociais do Município de Campinas. Campinas: Vigilância Socioassistencial, 2016. Disponível em: <https://smcais-vis.campinas.sp.gov.br/sites/ smcais-vis.campinas.sp.gov.br/files/arquivos/relatorio_de_informacoes_sociais_campinas_-_2016_0. pdf>. Acesso em: 19. Out. 2017.

NEGRÃO, Lísias Nogueira. Refazendo Antigas e Urdindo Novas Tramas: Trajetórias do Sagrado. Religião e Sociedade, Rio de Janeiro, v. 18, n. 2, p. 63-74, 1997. 